\title{
Student Perceptions of Nursing Research Following an Experiential Learning Activity
}

\author{
Carrie A. Hall* \\ School of Nursing and Health Sciences, Florida Southern College \\ 111 Lake Hollingsworth Rd, Lakeland, Florida, USA \\ E-mail: chall2@flsouthern.edu \\ Christy Skelly \\ School of Nursing and Health Sciences, Florida Southern College \\ 111 Lake Hollingsworth Rd, Lakeland, Florida, USA \\ E-mail: cskelly@flsouthern.edu \\ Carrie Risher \\ School of Nursing and Health Sciences, Florida Southern College \\ 111 Lake Hollingsworth Rd, Lakeland, Florida, USA \\ E-mail: crisher@flsouthern.edu \\ Maria Pagano \\ School of Nursing and Health Sciences, Florida Southern College \\ 111 Lake Hollingsworth Rd, Lakeland, Florida, USA \\ E-mail: mariapagano.mcp@gmail.com
}

This research did not receive any specific grant from funding agencies in the public, commercial, or not-forprofit sectors.

\section{Abstract}

Many undergraduate nursing students fail to appreciate the importance of research and its role in guiding practice. Education promoting nursing research is critical to guide nursing practice and to ensure patient quality and safety. Experiential learning activities may provide opportunities to move undergraduate nursing research beyond the traditional classroom setting to a more engaged learning experience. This study evaluated the student's perceptions on nursing research following an experiential learning opportunity during their senior year in a community health course. Data were collected in May 2017 from 19 nursing students via a paper-pencil survey including open ended questions. Two independent members of the research team completed content analysis. The results suggest three major themes: 1) nursing research is valuable to guide practice; 2) research requires planning and organization; and 3) patients benefit by research participation. Results of the study indicated experiential learning activities may foster student appreciation of nursing research and its role in improving patient care.

Keywords: experiential learning, nursing education, qualitative study, undergraduate research

DOI: $10.7176 / \mathrm{JEP} / 10-18-02$

Publication date:June $30^{\text {th }} 2019$

\section{Introduction}

Healthcare continues to exponentially change and nurses are faced with an evolving practice environment that requires new ways of viewing knowledge. A few of the changes nurses face in the twenty-first century include: changes in social and economic factors influencing access to health care; evolving understanding of the role of genetics and microbiomes as major determinants of health and healthcare delivery; and new uses of technology to guide diagnosis and treatment of diseases (McCormick \& Calzone, 2016; Salmond \& Echevarria, 2017). No longer can nurses continue to practice in unchanging silos. Instead, nurses must be equipped to use research to guide and change practice.

Nursing research is critical to guide nursing practice, shape healthcare policy, and ensure patient quality and safety (ANA, 2010). Despite this known and pivotal role of research in nursing, many undergraduate nursing students fail to appreciate research as a tool to inform practice (Johnson et al., 2010; McCurry and Martins, 2010). Developing effective methods of fostering an appreciation for nursing research are needed. Several studies have outlined the benefits of undergraduate nursing research experiences (Tingen et al., 2009). However, these experiences have only included a small number of students. Educators must think creatively to develop research learning opportunities for all undergraduate students. The purpose of this study was to evaluate students' perspectives of an entire class participating in an experiential learning project within a community health course. 


\section{Background}

\subsection{Undergraduate Nursing Research}

As the landscape of healthcare changes, research is necessary to evaluate not only the changes that are occurring but also the appropriate nursing responses. The need to maintain expertise in a given discipline requires healthcare professionals to be able to identify credible research findings and translate these findings into practice. Nurses are not only expected to demonstrate clinical expertise, but also to use and create research evidence to guide practice (Institute of Medicine [IOM], 2010). Baccalaureate nursing education should include content that exposes students to research processes that aids students in appreciating research as essential in guiding nursing practice (AACN, 2006). Nursing graduates must be prepared to appraise research for practice change and participate in scholarly endeavors. Despite the growing need to prepare baccalaureate nurses to use and participate in research to ensure quality care, many student nurses expressed negativity toward the review of research and practice standards to guide practice (Brown et al., 2010; Fiset et al., 2017). Keib et al. (2017) noted that students' voiced appreciation and confidence in research following delivery of a traditional didactic course. However, students failed to have a significant improvement in their plans to use research to guide practice or participate in future research.

Nursing students have previously indicated that they do not feel prepare to participate in research or to use research findings in the clinical setting (Meherali et al., 2017). Educators must now address this needed curricular change. Benner et al. (2010) have recommended a shift from "decontextualized knowledge" toward integration of research across all settings. Traditional methods of education have failed to foster student appreciation of the use of research to guide evidence-based practice (EBP) (Aglen, 2016; Wong et al., 2013). Innovative ideas are needed to transform student experiences with research and EBP. As educators, we must create learning environments that allow students the opportunity to actively engage in research.

\subsection{Theoretical Framework: Experiential Learning}

Experiential learning is a process of redefining constructs of knowing through a cycle of engaged learning experiences followed by personal reflection (Dewey, 1938; Kolb, 1984). Within this process, learners experience information through the immersion of concrete reality and symbolic representation (Holman et al., 1997). Kolb (1984) identified four components within the Experiential Learning Theory. These components take the learner from acquisition of concepts through thoughtful and reflective application in a variety of situations. The learner is first exposed to a new experience or situation (concrete experience) that allows for reflective observation of the experience. During the reflection, the student evaluates their previous understanding and any new insights gleaned during the experience. This reflective practice provides opportunities for reinforcement or modifications of the student's previous abstract understanding of the concept (abstract conceptualization). The student is then able to take the refined understanding and apply it to new situations to gain further understanding of the concept (active experimentation).

Experiential learning provides the student opportunities to engage in a transformative learning process through knowledge application and reflective practice (Lisko \& O'Dell, 2010). Transformative learning processes have been validated in multiple fields of study, including nursing (McGuire et al., 2017). Because nursing is a discipline in which varied skills and approaches to care are utilized, experiential learning is consistently threaded throughout the education of the nursing student. Some examples of experiential learning in nursing education include: the practice of flipping the classroom, where the students review an assigned lecture prior to the start of class, use of engaged learning activities such as small group activities, simulation, community outreach, and gaming (Glover et al., 2017; Koivisto et al., 2017; \& Victor, 2017). Merely being involved in an experiential learning scenario does not automatically transfer into learning. Students must comprehend the occurrence and then reflect on the learning that transpired. Reflecting on comprehension will impact development of judgment or a more profound learning experience (Lisko \& O’Dell, 2010). This study was to evaluate students' reflective understanding of nursing research following their active participation in a research study event. The goal was to determine sexual health knowledge of female undergraduate college students after completion of a sex health education event.

\section{Methods}

Senior level nursing students, at a private liberal arts college, participated in an Institutional Review Board (IRB) approved faculty led research study entitled "What's up Down There" (Skelly, et al. 2018). Students actively participated in all aspects of the research including recruitment, obtaining consent, delivery of the intervention, pre and post-testing, and data analysis.

To evaluate the students' perceptions on nursing research following the experiential learning opportunity, the senior community health nursing students $(\mathrm{N}=32)$ were invited to participate in a secondary study. These students were fourth year nursing student is a traditional pre-licensure program. Reflective narratives regarding student perceptions of nursing research after engagement in the experiential learning activity were collected. 
Student participants were asked to share their opinions about the importance of nursing research; their future plans related to research; insights gained by participating in the experiential learning activity; and the impact the "What's up Down There" study had on the participants.

Data from the narratives were coded by similar phrases and words and then cross-checked by a second member of the research team. Next, emergent themes were identified and compared to the original narratives by two independent members of the research team. Associated phrases were linked to the emergent themes and compared to the original narratives. The themes identified by both independent members of the research team were then compared for final consensus. Final themes and associated phrases were presented to student participants to ensure trustworthiness of the findings.

\subsection{Ethical Considerations}

The study received IRB approval from the participating college and administrative approval from the nursing school to access the student population. Students who agreed to voluntarily participate in the study provided informed consent. Those who participated were advised that they could excuse themselves from the study at any time. Confidentiality was maintained by use of numeric codes. Participants were notified that results would be reported in presentations and publications.

\section{Results}

A total of 19 of the 31 invited students $(59.4 \%)$ participated in the study. Participants were mainly female students $(\mathrm{n}=17 ; 89.4 \%)$. All participants had completed a required nursing evidence-based practice (EBP) course the previous semester. Content analysis of written reflections about the students 'experiences revealed three primary themes: 1) nursing research is valuable to guide practice; 2) patients are benefited by research participation; and 3) research requires planning and organization. Some students indicated that, before the experience, they felt intimidated by research and that the experience increased understanding of how research is conducted and the critical importance it plays in nursing. While some of the students indicated a desire to participate in research $(n=8)$, the majority $(n=11)$ noted that they still did not want to "conduct" research but now had a greater understanding of the process.

\subsection{Nursing Research is Valuable to Guide Practice}

All participants $(n=19)$ expressed a change in their views on the importance of research to guide practice. Students discussed their increased appreciation of nursing research and that the experience was much different than they had expected. One participant wrote "How are we going to make advances in our community if we don't continue to learn about and question our practices? We can only do this by engaging in research." Another participant shared "I found this to be a great experience and a wonderful way to expand current knowledge and help educate the community." The experiential learning activity also reinforced some students' (n $=8$ ) desire to engage in future research: "This experience has reaffirmed my desire to participate in nursing research." Other students wrote about the importance of research but that they did not want to engage in research ( $\mathrm{n}=11)$. For example, one student wrote: "I'd rather be taking care of patients, hands on, than researching. But I see the need for research in nursing practice." Another student wrote, "Right now I want to focus on developing my clinical practice."

\subsection{Patients are benefited by Research Participation}

Almost all participants $(n=18)$ noted that the community participants benefited from the research intervention provided during the "What's up Down There," study. Students indicated excitement in providing the intervention. Many indicated they were surprised at how little community participants knew prior to the event. Examples from the student narratives include: "I learned how much individuals benefit from teaching. Seeing how much they didn't know made me more eager." and "It was interesting to see how much the intervention helped others." Participant narratives also discussed the increased knowledge provided by the intervention: "I think it benefited them in a way that they now have knowledge on sexual health. They are better able to protect themselves and understand their bodies."

\subsection{Research Requires Planning and Organization}

Despite recent completion of an evidence-based practice course, student participants expressed a greater appreciation for the research process. For example, student participants wrote: "I learned a lot about how research studies are developed and how important patient education is." and "I take it a lot more seriously now." Additionally, students expressed how the experiential learning activity helped them to fully understand the research process. Student comments included:

\section{- I Iearned about the process of human subject research and everything that goes into the development of} a research study. 
- $\quad$ Through this experience I gained insight into the benefits of research and how interesting it can be.

- $\quad$ A lot goes into the whole process and how to get people involved.

- I know more about the research process.

- $\quad$ I gained more knowledge about statistics and how much is involved in research.

- I I was surprised by the amount of different steps involved in research study.

- Ifeel that the experience reinforced the research experience.

- I Ididn't realize how much went into a research study. Planning is essential.

\subsection{Other Insights}

Two participants provided unique insights into possible benefits of experiential learning opportunities. While these narratives did not reveal common themes among all participants, they did reveal other possible benefits of the experiential learning activity. One student narrative supported the growth in empathetic nursing care. The student noted, "The experience helped me judge others less." This response was unexpected but powerful. Experiential learning activities, like this one, may help students reflect on their biases and preconceived perceptions about patients. The activity facilitated reflection in this participants views. Another student narrative identified was, "Teaching people is fun, but the group work to develop the study and intervention was not. It is difficult to work in groups. It showed me a different aspect of nursing school and helped me learn to work as a group." While the activity was designed to allow students an opportunity to apply concepts of research in a "real world" situation and refine their understanding of nursing research, this student narrative highlights the benefit of learning "group work." Experiential learning activities may provide novel opportunities to promote collaboration.

\section{Implications}

Students in this study expressed a greater appreciation for nursing research, including the benefits for patient care and the process involved in development and implementation of a study. Despite this new appreciation, many continued to deny interests in conducting research in the near future. Similar results were found with the delivery of a traditional didactic course (Keib et al. 2017). This is not surprising given the period of transition from student nurse to professional nurse is filled with uncertainty and anxiety for students (Duchscher, 2009). During the period of transition, the student nurse must develop the skills necessary to practice in the clinical environment. The new nurse must practice in an environment that requires fine-tuned critical analysis skills as well the ability to deliver safe and appropriate care (Benner et al., 2010).

Experiential learning focused on nursing research may provide a unique advantage over traditional class room didactic delivery. Students in this study gained insights into all aspects of the research process, as in a traditional classroom. However, the experiential learning activity also provided students hands on experience, insights into the benefits of research for participants, and practice working in a group setting. During the experience, students reflected and evaluated their previous understanding of nursing research and any new insights gleamed during the experience $(\mathrm{Kolb}, 1984)$. This reflective practice provides opportunities for reinforcement or modifications of the student's previous abstract understanding of nursing research.

\section{Limitations}

Two major limitations are noted in the study. First, due to the learning objectives of the community health course, faculty purposely arranged an experience that focused on population-based health. The experience included a community-based health education intervention for college age students but did not include hospital based experiences. Therefore, the results of this study may not be generalizable to nursing students who engage in experiential learning experiences in acute care settings. Second, participants in this study were predominately young, Caucasian, female, from a private liberal arts college. The lack of a heterogeneous sample is not unusual in many nursing programs, but future research is needed to adequately capture the experiences of minority nursing students.

\section{Conclusion}

This study found that an experiential learning activity, focused on research application, within a community health nursing course was valuable for undergraduate nursing students. Students' reflective narratives provided evidence that the experiential activity allowed students to take didactic knowledge about research and apply it to a community health promotion project. The use of experiential learning may enhance traditional research/ EBP courses and allow a student to more fully appreciate its importance in guiding practice. Future studies are needed to explore the benefits of experiential learning in nursing scholarship. Focus on translational research with the use of experiential learning may foster improved student perceptions on the benefits for practice. 


\section{References}

Aglen, B., 2016. Pedagogical strategies to teach bachelor students evidence-based practice: A systematic review. Nurse Education Today, 36, 255-263. doi:10.1016/j.nedt.2015.08.025

American Association of Colleges of Nursing. 2010. The essentials of baccalaureate education for professional nursing practice. Retrieved from: http://www.aacn.nche.edu/Education/pdf/ BaccEssentials08.pdf.

American Association of Colleges of Nursing, 2006. Nursing research. Retrieved from: http://www.aacn.nche.edu/publications/position/nursingresearch

Benner, P., Sutphen, M., Leonard, V., Day, L., 2010. Educating nurses: A call for radical transformation. San Franciso, CA: Jossey-Bass.

Brown, C.E., Kim, S.C., Stichler, J.F., Fields, W., 2010. Predictors of knowledge, attitudes, use and future use of evidence-based practice among baccalaureate nursing students at two universities. Nurse Education Today, 30, 521-527. doi:10.1016/j.nedt.2009.10.021

Dewey, J., 1938. Experience and education. New York: Collier Books.

Duchscher, J. 2009. Transition shock: the initial stage of role adaptation for newly graduated Registered Nurses. Journal of Advanced Nursing, 65(5), 1103-1113. doi:10.1111/j.1365-2648.2008.04898.x

Fiset, V. J., Graham, I. D., Davies, B. L., 2017. Evidence-based practice in clinical nursing education: A scoping review. Journal of Nursing Education, 56(9), 534-541. doi:10.3928/01484834-20170817-04

Glover, T.L., Horgas, S.L., Castleman, J., Turpening, P., \& Kittelson, S., 2017. An experiential learning approach to primary palliative care nursing education. Journal of Hospice \& Palliative Nursing 19(6), 534538.

Holman, D., Pavlica, K., Thorpe, R., 1997. Rethinking Kolb's theory of experiential learning in management education: The contribution of social constructionism and activity theory. Management Learning, 28 (2), 135-148. doi:10.1177/1350507697282003

Institute of Medicine (IOM), 2010. The future of nursing: Focus on education. Retrieved from http://iom.nationalacademies.org/Reports/2010/The-Future-of-Nursing-Leading-Change-AdvancingHealth/Report-Brief-Education.aspx?page $=2$

Johnson, N., List-Ivankovic, J., Eboh, W., Ireland, J., Adams, D., Mowatt, E., Martindale, S., 2010. Research and evidence based practice: using a blended approach to teaching and learning in undergraduate nurse education. Nurse Education in Practice, 10(1), 43-47. doi:10.1016/j.nepr.2009.03.012

Keib, C. N., Cailor, S. M., Kiersma, M. E., Chen, A. M. H., 2017. Changes in nursing students' perceptions of research and evidence-based practice after completing a research course. Nurse Education Today, 54, 37-43. doi:10.1016/j.nedt.2017.04.007

Koivisto, J., Niemi, H., Multisilta, J., \& Eriksson, E., 2017. Nursing students' experiential learning processes using an online \#D simulation game. Educ Inf Technol 22:383-398. doi 10.1007/s10639-015-9453-x

Kolb, D.A., 1984. Experiential learning: Experience as the source of learning and development. Upper Saddle River, New Jersey: Prentice-Hall.

Lisko, S. \& O'Dell, V., 2010. Integration of theory and practice: Experiential learning theory and nursing education. Nursing Education Perspectives 31(2), 106-108.

McCurry, M., Martins, D., 2010. Teaching undergraduate nursing research: a comparison of traditional and innovative approaches for success with millennial learners. Journal of Nursing Education, 49(5), 276-279. doi:10.3928/01484834-20091217-02

McCormick, K. A., \& Calzone, K. A. (2016). The impact of genomics on health outcomes, quality, and safety. Nursing Management, (4), 23. Doi: 10.10974-01.NUMA.0000481844.50047.ee

McGuire, M., Goldstein, C., Claywell, L., Patton, R., 2017. Analysis of Student Reflections of Experiential Learning in Nursing Health Policy Courses. Nurse Educator, 42(2), 95-99. doi:10.1097/NNE.0000000000000321

Meherali, S. M., Paul, P., Profetto-McGrath, J., 2017. Use of research by undergraduate nursing students: A qualitative descriptive study. Qualitative Report, 22(2), 634-654.

Salmond, S. W., \& Echevarria, M. (2017). Healthcare transformation and changing roles for nursing. Orthopaedic Nursing, 36(1), 12-25. doi: 10.1097/NOR.0000000000000308

Skelly, C., Hall. C.A., Brown, B., Risher, C. (2018). Peer Education of College Females on Reproductive Health. Universal Journal of Educational Research, 6(5), 844-847. DOI: 10.13189/ujer.2018.060505

Tingen, M.s., Burnett, A.H., Murchison, R.B., Zhu, H., 2009. The importance of nursing research. Journal of Nursing Education, 48(3), 167-170.

Victor, J., 2017. Improving Clinical Nursing Judgement in Prelicensure Students. Journal of Nursing Education, 56 (12), 733-736

Wong, S.E., McEvoy, M.P., Wiles, L.K., Lewis, L.K., 2013. Magnitude of change in outcomes following entrylevel evidence-based practice training: A systematic review. International Journal of Medical Education, 4, 107-114. doi:10.5116/ijme.51a0. 